\title{
Correction: Combined Use of Web-Based and In-Person Education on III Health Self-management Skills in Adults With Bipolar Disorder: Protocol for a Mixed Methods Study
}

Anna Hatzioannou ${ }^{1}$, BSc, MSc; Andreas Chatzittofis ${ }^{2}, \mathrm{MD}, \mathrm{PhD}$; Virginia Sunday Koutroubas ${ }^{1}$, BA, MSc; Evridiki Papastavrou $^{1}$, BSc, MSc, PhD; Maria Karanikola ${ }^{1}$, BSc, MSc, PhD

${ }^{1}$ Nursing Department, School of Health Sciences, Cyprus University of Technology, Limassol, Cyprus

${ }^{2}$ Medical School, University of Cyprus, Nicosia, Cyprus

Corresponding Author:

Maria Karanikola, BSc, MSc, PhD

Nursing Department

School of Health Sciences

Cyprus University of Technology

15 Vragadinou Street

Limassol, 3041

Cyprus

Phone: 35799786069

Fax: 35725002012

Email: maria.karanikola@cut.ac.cy

\section{Related Article:}

Correction of: https://www.researchprotocols.org/2021/9/e25168

(JMIR Res Protoc 2021;10(9):e33506) doi: 10.2196/33506

In "Combined Use of Web-Based and In-Person Education on Ill Health Self-management Skills in Adults With Bipolar Disorder: Protocol for a Mixed Methods Study" (JMIR Res Protoc 2021;10(9):e25168) one error was noted.

One author's name was displayed as:

Andreas Hatzittofis

It has now been corrected to:

\section{Andreas Chatzittofis}

The correction will appear in the online version of the paper on the JMIR Publications website on September 15, 2021, together with the publication of this correction notice. Because this was made after submission to PubMed, PubMed Central, and other full-text repositories, the corrected article has also been resubmitted to those repositories.

This is a non-peer-reviewed article. Submitted 10.09.21; accepted 10.09.21; published 15.09.21.

Please cite as:

Hatzioannou A, Chatzittofis A, Koutroubas VS, Papastavrou E, Karanikola M

Correction: Combined Use of Web-Based and In-Person Education on Ill Health Self-management Skills in Adults With Bipolar Disorder: Protocol for a Mixed Methods Study

JMIR Res Protoc 2021;10(9):e33506

URL: https://www.researchprotocols.org/2021/9/e33506

doi: $10.2196 / 33506$

PMID:

(C)Anna Hatzioannou, Andreas Chatzittofis, Virginia Sunday Koutroubas, Evridiki Papastavrou, Maria Karanikola. Originally published in JMIR Research Protocols (https://www.researchprotocols.org), 15.09.2021. This is an open-access article distributed under the terms of the Creative Commons Attribution License (https://creativecommons.org/licenses/by/4.0/), which permits unrestricted use, distribution, and reproduction in any medium, provided the original work, first published in JMIR Research 
Protocols, is properly cited. The complete bibliographic information, a link to the original publication on https://www.researchprotocols.org, as well as this copyright and license information must be included. 